\title{
Interleukin-6, vascular endothelial growth factor and transforming growth factor beta 1 in canine steroid responsive meningitis-arteritis
}

\author{
Arianna Maiolini ${ }^{1,2^{*}}$, Meike Otten ${ }^{3}$, Marion Hewicker-Trautwein ${ }^{4}$, Regina Carlson ${ }^{1}$ and Andrea Tipold ${ }^{1,2}$
}

\begin{abstract}
Background: Steroid Responsive Meningitis-Arteritis (SRMA) is a common cause of inflammation of the canine central nervous system (CNS). To investigate if transforming growth factor beta 1 (TGF- $\beta_{1}$ ), interleukin-6 (IL-6) and vascular endothelial growth factor (VEGF) are involved in the production of excessive immunoglobulin A (IgA), the induction of acute phase proteins and in the development of a systemic necrotizing vasculitis, characteristic of SRMA, these three signalling proteins were evaluated.
\end{abstract}

Results: Cerebrospinal fluid (CSF) and serum samples of dogs during the acute phase of SRMA (SRMA) were tested for IL-6, VEGF and TGF- $\beta_{1}$. Results were compared to those of dogs affected with SRMA during treatment (SRMA Th) and during relapse (SRMA R), to dogs with other meningoencephalomyelitides (ME), with miscellaneous non-inflammatory diseases of the CNS (CNS-Mix), with idiopathic epilepsy (IE), with systemic inflammatory diseases (Syst. Infl.) and with healthy dogs (Healthy). Concentrations of IL-6 and VEGF in CSF were significantly elevated in the SRMA group compared to the other disease categories $(p<0.05)$. The CSF concentrations of TGF- $\beta_{1}$ were increased in SRMA group, but statistically significant differences were found only in comparison with Healthy and CNS-Mix groups. No differences were detected in the serum concentrations of TGF- $\beta_{1}$ between the different groups. In untreated SRMA patients, a positive correlation ( $r_{\text {spear }}=0.3549 ; P=0.0337$ ) between concentrations of TGF- $\beta_{1}$ and IgA concentration was found in CSF, while concentrations of IL- 6 and VEGF in CSF positively correlated with the degree of pleocytosis ( $r_{\text {spear }}=0.8323 ; P<0.0001$ and $r_{\text {spear }}=0.5711 ; P=0.0166$, respectively).

Conclusions: Our results suggest that these three signalling proteins are biomarkers of disease activity in SRMA. VEGF might play an important role in the development of a systemic arteritis. TGF- $\beta_{1}$ is considered to be involved in the excessive IgA production, while IL-6 in the pleocytosis. The combined intrathecal increase of TGF- $\beta_{1}$ and IL-6 detected in SRMA could possibly force CD4 progenitors to differentiate towards the newly described Th17 lymphocyte subset and enhance the autoimmune response.

Keywords: Steroid responsive meningitis-arteritis (SRMA), Interleukin-6 (IL-6), Transforming growth factor beta 1 $\left(\right.$ TGF- $\left.\beta_{1}\right)$, Vascular endothelial growth factor (VEGF), Cerebrospinal fluid (CSF), Dog, Central nervous system (CNS)

\section{Background}

Steroid Responsive Meningitis-Arteritis (SRMA) is a relatively common inflammatory disease of the canine central nervous system (CNS) [1], being the primary cause of meningitis [2,3] and one of the most common causes of fever in referred dogs [4]. Typically affected dogs manifest

\footnotetext{
* Correspondence: arianna.maiolini@tiho-hannover.de

${ }^{1}$ Department of Small Animal Medicine and Surgery, University of Veterinary Medicine, Hannover, Germany

${ }^{2}$ Center for Systems Neuroscience, Hannover, Germany

Full list of author information is available at the end of the article
}

severe neck pain in addition to signs of systemic illness, such as fever and lethargy. The meningeal and systemic inflammation is usually reflected by laboratory findings, such as pleocytosis and leukocytosis [5] and the elevation of acute phase proteins [6-8]. A concurrent increased intrathecal and systemic production of immunoglobulin A (IgA) has been found in dogs affected with SRMA [9], and its determination supports the diagnosis [10]. Recent studies underlined the importance of a Th2-mediated immune response in SRMA patients [11,12], but the exact etiopathogenesis of the disease is still unclear.

\section{Biomed Central}


Signalling proteins are molecules, such as cytokines, growth factors, hormones and neurotransmitters, that interact with receptors. Vascular Endothelial Growth Factor (VEGF) is a potent, multifunctional factor, which regulates angiogenesis and blood vessel permeability $[13,14]$. In the last two decades the role of VEGF has been widely investigated in systemic vasculitides [15-17] and malignant tumours $[18,19]$. In veterinary medicine VEGF has been studied in some inflammatory diseases [20] and tumours [21,22], but its role in systemic vasculitis is still unknown. Interleukin 6 (IL-6) is a proinflammatory cytokine, which activates lymphocytes, increases antibody production, induces fever and acute-phase protein production [23], while Transforming Growth Factor Beta 1 (TGF- $\beta_{1}$ ) induces a class switching of B lymphocytes towards IgA production [24].

To test the hypothesis that the signalling proteins VEGF, IL- 6 and TGF- $\beta_{1}$ are involved in the pathogenesis of SRMA, these proteins were determined in cerebrospinal fluid (CSF) and serum. We hypothesize that enhanced VEGF production is responsible for the increased vascular permeability (vasculitis) observed in SRMA dogs, while IL- 6 and TGF- $\beta_{1}$ are responsible for the excessive IgA production and the systemic inflammatory response, especially for acute phase protein production and development of T-helper cell subtypes.

\section{Methods}

\section{Serum and cerebrospinal fluid (CSF) samples}

Serum and cerebrospinal fluid (CSF) samples were collected from client-owned dogs, presented to the Neurology Service of the Department of Small Animal
Medicine and Surgery, University of Veterinary Medicine, Hannover, Germany, according to the Universities rules.

All dogs underwent a standard neurological examination performed either by a veterinary neurology resident or a board-certified veterinary neurologist. Depending on the diagnosis, animals were assigned to one of the following groups (see Table 1): 'SRMA untreated' (SRMA), 'SRMA relapse' (SRMA R), 'SRMA therapy' (SRMA Th), 'idiopathic epilepsy' (IE), 'Meningoencephalomyelitides' (ME), and 'miscellaneous non-inflammatory CNS diseases' (CNS-Mix).

Diagnoses were based on the results of general and neurological examinations, complete blood cell count $(\mathrm{CBC})$, blood chemistry, CSF analysis and further specific diagnostic procedures if considered useful to achieve a definitive or 'highly likely' diagnosis (e.g. radiographic and ultrasound examination, electrodiagnostics, computed tomography, magnetic resonance imaging, surgery, histopathology).

Dogs not suffering from neurological conditions, but otherwise affected with systemic inflammatory diseases were also included in the study ('Syst. Inflam.').

Healthy dogs with a normal general and neurological examination and laboratory values in the reference range served as negative control group ('Healthy').

CSF and serum samples were stored at $-20^{\circ} \mathrm{C}$ until batch analyzed.

The study was conducted following the ethical guidelines of the University for Veterinary Medicine Hannover. The experimental protocols and procedures in healthy dogs were performed in accordance with the European Communities Council Directive of 24 November $1986(86 / 609 / \mathrm{EEC})$ and were approved by the

Table 1 Distribution of disease categories

\begin{tabular}{|c|c|}
\hline Groups & Findings and number of dogs \\
\hline SRMA untreated (SRMA) & $\begin{array}{l}\text { Dogs with fever, cervical pain, neutrophilic leukocytosis and pleocytosis. } \\
\text { These dogs were not pre-treated with glucocorticosteroid }(n=36)\end{array}$ \\
\hline SRMA relapse (SRMA R) & $\begin{array}{l}\text { Dogs with a previous diagnosis of SRMA in which clinical signs recurred } \\
\text { despite glucocorticosteroid treatment }(n=9)\end{array}$ \\
\hline SRMA therapy (SRMA Th) & $\begin{array}{l}\text { Dogs with previous diagnosis of SRMA under long-term } \\
\text { glucocorticosteroid treatment. These dogs did not show any clinical } \\
\text { signs at the time of sampling }(n=20)\end{array}$ \\
\hline Idiopathic epilepsy (IE) & $\begin{array}{l}\text { Dogs with clinical, CSF, MRI findings consistent with idiopathic epilepsy } \\
(\mathrm{n}=22)\end{array}$ \\
\hline Meningoencephalomyelitides (ME) & $\begin{array}{l}\text { Dogs with clinical, CSF, MRI and/or pathological findings consistent with } \\
\text { meningoencephalomyelitides: granulomatous meningoencephalomyelitis } \\
(n=14) \text {, necrotising encephalitides }(n=1) \text {, meningoencephalomyelitis of } \\
\text { unknown origin }(n=8) \text {, infectious encephalitides }(n=24)\end{array}$ \\
\hline Miscellaneous non-inflammatory CNS diseases (CNS-Mix). & $\begin{array}{l}\text { Dogs with miscellaneous not primarily inflammatory neurological } \\
\text { diseases: intervertebral disc disease }(n=9) \text {, neoplasia of the CNS }(n=24) \text {, } \\
\text { cerebrovascular disease }(n=4) \text {, degenerative myelopathy }(n=1)\end{array}$ \\
\hline Systemic inflammatory diseases (Syst. Inflam.) & $\begin{array}{l}\text { Dogs affected with systemic inflammatory diseases, but not suffering from } \\
\text { neurological conditions }(n=16)\end{array}$ \\
\hline Healthy & Healthy dogs $(n=20)$ \\
\hline
\end{tabular}

CSF: cerebrospinal fluid; CNS: central nervous system; MRI: magnetic resonance imaging; SRMA: steroid-responsive meningitis-arteritis. 
authorities in Lower Saxony (animal experiment number 33.42502/05-12.05).

\section{Quantification of IL-6}

Serum and CSF IL-6 concentrations were measured with a commercially available canine-specific Enzyme Linked Immunosorbent Assay (ELISA) following manufacturer's instructions (Quantikine Canine IL-6 Immunoassay; R\&D Systems, Minneapolis, MN, USA). The mean minimum detectable value given by the manufacturer was $6.1 \mathrm{pg} / \mathrm{mL}$. Values lower than $6.1 \mathrm{pg} / \mathrm{mL}$, were considered negative for IL-6. If the value ranged between $6.1 \mathrm{pg} / \mathrm{mL}$ and the highest dilution of the standard curves $(31.25 \mathrm{pg} / \mathrm{mL})$ a fixed value of $3 \mathrm{pg} / \mathrm{mL}$ was assigned for statistical analysis. If the value exceeded the highest value of the standard curve $(2000 \mathrm{pg} / \mathrm{mL})$, the sample was diluted and measured again.

All samples were analyzed in duplicates and mean values were calculated.

The IL- 6 bioactivity in serum and CSF was verified testing its ability to stimulate proliferation of B9 cell line, a mouse $\mathrm{B}$ cell murine hybridoma cell line that requires IL-6 for survival and proliferation (DSMZ No ACC 211, German Collection of Microorganisms and Cell Cultures, DSMZ, Braunschweig, Germany) [25-28].

Cells were cultured at $37^{\circ} \mathrm{C}$ and $5 \% \mathrm{CO}_{2}$ in Rosewell Park Memorial Institute (RPMI) 1640 medium with Lglutamine $\left(\right.$ Gibco $^{\circledR}$ RPMI Media 1640) containing 10\% heat-inactivated fetal bovine serum, $50 \mathrm{pg} / \mathrm{mL}$ recombinant canine IL-6 (rcIL-6) (Recombinant Canine IL-6; R\&D Systems, Minneapolis, MN, USA) and $50 \mu \mathrm{M} \mathrm{2-}$ mercaptoethanol.

Cells for the assay were washed twice in the above described medium without IL-6. For each assay, a standard curve was prepared using rcIL-6 with serial threefold dilutions starting at $200 \mathrm{pg} / \mathrm{mL}$.

Samples were tested in duplicates at dilutions ranging from 1:2 to 1: 240.

For the IL-6 bioactivity assay B9 cells (5000 cells/well) were incubated for 48 hours with rcIL-6 standard dilutions or diluted canine CSF and serum samples in opaque 96well microtiter plates (F96 MicroWell $^{\text {TM }}$ Plates, Nunc ${ }^{\text {TM }}$, Denmark). Cell proliferation and viability was quantified using the CellTiter-Glo ${ }^{\circledR}$ Luminescent Cell Viability Assay (Promega, Madison, WI), according to manufacturer's recommendations. Luminescence in each well was measured $30 \mathrm{~min}$ after reagent addition using a scanning multiwell spectrophotometer equipped with the analysis software Gen 5 (Synergy2 HT multi-mode microplate reader, BioTek Instruments Inc., Bad Friedrichshall Germany).

\section{Quantification of VEGF}

Serum and CSF VEGF concentrations were measured with commercially available canine-specific ELISA following manufacturer's instructions (Quantikine Canine VEGF Immunoassay, R\&D Systems, Minneapolis, MN, USA). The minimum detectable values given by the manufacturer were $<9.8 \mathrm{pg} / \mathrm{mL}$ for CSF and $<19.5 \mathrm{pg} / \mathrm{mL}$ for serum. Similarly as described for the IL-6 ELISA, a content of $0 \mathrm{pg} / \mathrm{mL}$ was assigned if the amount of VEGF detected was less than the minimum detectable concentration.

If the amount ranged between $9.8 \mathrm{pg} / \mathrm{mL}$ for CSF or $19.5 \mathrm{pg} / \mathrm{mL}$ for serum and the highest dilution of the standard curves $(19.5 \mathrm{pg} / \mathrm{mL}$ and $39.1 \mathrm{pg} / \mathrm{mL}$, respectively) a fixed value of $2 \mathrm{pg} / \mathrm{mL}$ and $3.9 \mathrm{pg} / \mathrm{mL}$ instead of zero was assigned for statistical analysis.

All samples were analyzed in duplicates and mean values were calculated.

\section{Quantification of TGF- $\beta_{1}$}

Serum and CSF TGF- $\beta_{1}$ concentrations were measured with a commercially available ELISA following manufacturer's instructions (Human TGF-beta 1 DuoSet, R\&D Systems, Minneapolis, MN, USA ). This assay is designed to detect the biologically active natural and recombinant human TGF- $\beta_{1}$. Canine TGF- $\beta_{1}$ shares $94 \%$ nucleotide sequence identity to human TGF- $\beta_{1}$ [29]. Therefore, we suspected a relative high cross-reactivity that allows the measurement of canine TGF- $\beta_{1}$ by using this human ELISA Development Kit. The final dilution was 1:15 for the CSF samples and 1:30 and 1:60 for the serum samples. All dilutions were tested in duplicates on 96-well microplates (Nunc-Immuno ${ }^{\mathrm{TM}}$-Plate, Nunc ${ }^{\mathrm{TM}}$, Denmark). The absorbance was recorded at a wavelength of $450 \mathrm{~nm}$ using a plate reader (Dynatech, Denkendorf, Germany).

Antibodies were tested by immunohistochemistry (IHC) detecting canine TGF- $\beta_{1}$ on canine tissue. Different canine tissues (activated lymph nodes, brain tumour, brain and spinal cord from SRMA affected dogs) were stained with the capture antibody of the previously mentioned ELISA-Kit. All tissues were routinely formalinfixed and paraffin-embedded and the sections were mounted on positively charged slides (SuperFrost Plus ${ }^{\circledR}$, Menzel-Gläser, Wiesbaden, Germany). Tissue sections were deparaffinised and the endogenous peroxidase was blocked with $0.5 \% \mathrm{H}_{2} \mathrm{O}_{2}$ in $70 \%$ ethanol over 30 minutes. After washing the slides with PBS three times for five minutes, citrate buffer (10 minutes, autoclave, $\left.121^{\circ} \mathrm{C}\right)$ was used for antigen retrieval. The capture antibody of the ELISA-Kit, a monoclonal mouse-anti-human TGF$\beta_{1}$-antibody was diluted $1: 40$ in PBS (pH 7.5) with $1 \%$ bovine serum albumin (BSA) and incubated overnight by $4^{\circ} \mathrm{C}$. As secondary antibody we used a biotinylated goatanti-mouse-antibody (Vector Laboratories, Burlingame, USA) (diluted 1:200 in PBS, incubation for 45 minutes, room temperature). Staining was completed using an $\mathrm{ABC}$ Kit (Vector Laboratories, Burlingame, USA). 


\section{Quantification of $\lg A$}

Serum and CSF IgA concentration were measured in 31 dogs with 'untreated SRMA' using an ELISA, as previously described [9].

\section{Data analysis}

Data were analyzed for normal distribution using the Kolmogorov-Smirnov test, and non-parametric tests were used to analyze data not conforming to a Gaussian distribution.

In addition to descriptive methods, the Kruskal-Wallis test was used to evaluate the analysis of variance. Multiple comparisons between the SRMA groups and groups of other diseases were performed using the Wilcoxon rank-sum test.

The Spearman's rank correlation coefficients $\left(\mathrm{r}_{\text {Spear }}\right)$ were calculated in the "SRMA untreated" group to detect correlations between signalling proteins and different parameters, such as IgA concentrations, complete blood cell count and CSF cell count.

Data were analyzed by using the statistical software package (GraphPad Prism ${ }^{\circledR}$, version 5; GraphPad Software, La Jolla, CA, USA) and values of $\mathrm{P}<0.05$ were considered significant.

\section{Results}

CSF and serum samples of 172 dogs were collected and analysed. In additional 36 dogs only serum was collected. The small amount of some of the samples did not allow performing the quantification of all three signalling proteins in each sample. The distribution of the samples for each ELISA is shown in Table 2.

\section{Quantification of IL-6}

IL-6 concentrations in CSF and serum and results of the statistical analysis are illustrated in Figure $1 \mathrm{~A}$ and $1 \mathrm{~B}$

Table 2 Number of CSF and serum samples analysed for each signalling protein in each group

\begin{tabular}{|c|c|c|c|c|c|c|}
\hline \multirow{2}{*}{$\frac{\text { Groups }}{\mathrm{n} \text { of samples }}$} & \multicolumn{2}{|l|}{ IL-6 } & \multicolumn{2}{|c|}{ VEGF } & \multicolumn{2}{|c|}{ TGF- $\beta_{1}$} \\
\hline & CSF & Serum & CSF & Serum & CSF & Serum \\
\hline SRMA & 26 & 28 & 21 & 28 & 36 & 35 \\
\hline SRMA R & 9 & 8 & 9 & 8 & 0 & 0 \\
\hline SRMA Th & 41 & 44 & 41 & 45 & 0 & 0 \\
\hline ME & 13 & 13 & 11 & 17 & 39 & 35 \\
\hline CNS-Mix & 21 & 22 & 18 & 20 & 29 & 26 \\
\hline Syst. Inflam. & 7 & 12 & 3 & 16 & 0 & 0 \\
\hline IE & 22 & 16 & 14 & 14 & 0 & 0 \\
\hline Healthy & 8 & 8 & 8 & 8 & 20 & 15 \\
\hline
\end{tabular}

IL-6: interleukin-6; VEGF: vascular endothelial grow factor; TGF- $\beta_{1}$ : Transforming growth factor beta; CSF: cerebrospinal fluid; CNS: central nervous system; SRMA: steroid-responsive meningitis-arteritis; Syst Inflam: systemic inflammatory diseases; ME: other inflammatory CNS diseases; CNS-Mix: miscellaneous non-inflammatory CNS diseases; IE: idiopathic epilepsy. and Table 3. The highest concentrations of IL-6 were detected in CSF of dogs with SRMA (median $1582 \mathrm{pg} / \mathrm{mL}$; range $163.1-3473 \mathrm{pg} / \mathrm{mL}$ ). This group differed significantly from the other disease categories, with the exception of dogs with relapsed SRMA (median $637.7 \mathrm{pg} / \mathrm{mL}$; range 17.19-1507 pg/mL).

Similarly, high concentrations of IL-6 were detected in serum in the 'SRMA' group (median $3 \mathrm{pg} / \mathrm{mL}$; range 3$124 \mathrm{pg} / \mathrm{mL}$ ), 'SRMA R' group (median $17.13 \mathrm{pg} / \mathrm{mL}$; range $3-36.24 \mathrm{pg} / \mathrm{mL}$ ) and 'Syst. Inflam.' group (median $17.13 \mathrm{pg} / \mathrm{mL}$; range $0-77.1 \mathrm{pg} / \mathrm{mL}$ ). In the remaining groups the IL-6 concentration was significantly lower than in the 'SRMA' group.

Approximately $30 \%$ of the samples used for the ELISA were also tested with the bioassay.

The B9 cells could proliferate only when incubated with samples with high IL-6 values measured by the ELISA.

\section{Quantification of VEGF}

VEGF concentrations in CSF and serum and results of the statistical analysis are illustrated in Figure 1C and 1D and Table 3.

The highest concentrations of VEGF were detected in CSF (median $36.31 \mathrm{pg} / \mathrm{mL}$; range $1-175.2 \mathrm{pg} / \mathrm{mL}$ ) and serum (median $43.92 \mathrm{pg} / \mathrm{mL}$; range $3.9-94.5 \mathrm{pg} / \mathrm{mL}$ ) of dogs with SRMA. Similarly, high concentrations of VEGF were found in CSF (median $20.80 \mathrm{pg} / \mathrm{mL}$; range 0-69.96 pg/mL) and serum (median $33.71 \mathrm{pg} / \mathrm{mL}$; range 0.98-42.9 $\mathrm{pg} / \mathrm{mL}$ ) of dogs with relapsed SRMA and in serum (median $3.9 \mathrm{pg} / \mathrm{mL}$; range $3.9-57.8 \mathrm{pg} / \mathrm{mL}$ ) of dogs with a systemic inflammatory disease. In the remaining groups the VEGF concentrations were significantly lower than the ones of the 'SRMA' group.

\section{Quantification of TGF- $\beta_{1}$}

TGF- $\beta_{1}$ concentrations in CSF and serum and results of the statistical analysis are illustrated in Figure $1 \mathrm{E}$ and $\mathrm{F}$ and Table 3.

Compared with the 'Healthy' group, TGF- $\beta_{1}$ concentrations in CSF were significantly higher in the 'SRMA' (median $90 \mathrm{pg} / \mathrm{mL}$; range $0-429 \mathrm{pg} / \mathrm{mL}$ ) and the ' $\mathrm{ME}$ ' (median $58 \mathrm{pg} / \mathrm{mL}$; range $0-214 \mathrm{pg} / \mathrm{mL}$ ) groups. In serum the 'SRMA' group showed the lowest concentrations of TGF- $\beta_{1}$ (median $13.57 \mathrm{ng} / \mathrm{mL}$, range 9.93$19.27 \mathrm{ng} / \mathrm{mL})$. These concentrations were significantly lower than those found in the remaining groups.

The capture antibody of the commercial human ELISA-Kit succeeded in staining canine TGF- $\beta_{1}$ in the canine tissues used as positive controls, such as lymph nodes with suppurative lymphadenitis and brain and spinal cord with SRMA (Figure 2). In the negative control sections no TGF- $\beta_{1}$ was detected. 


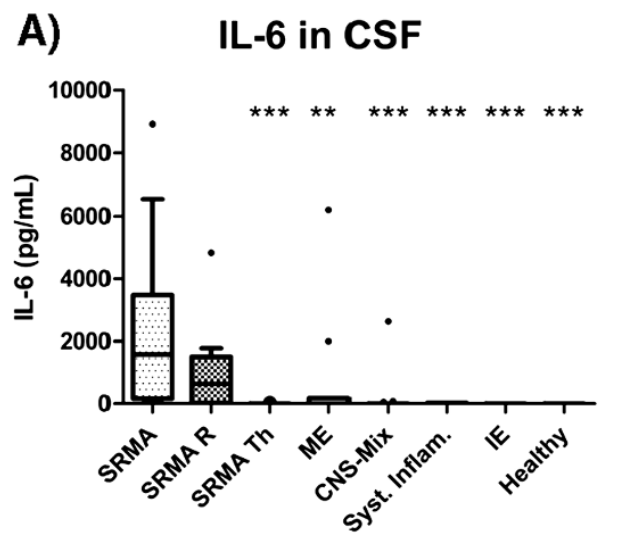

Groups

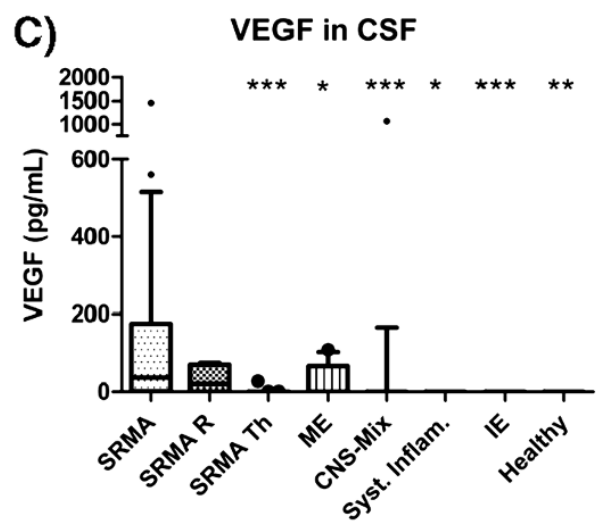

Groups

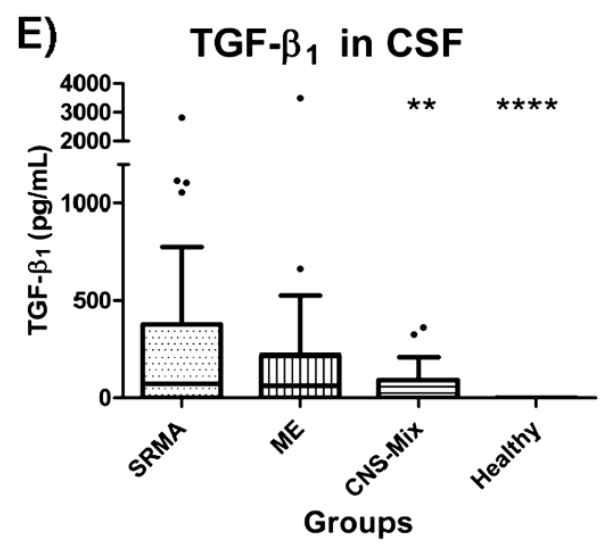

B) IL-6 in Serum
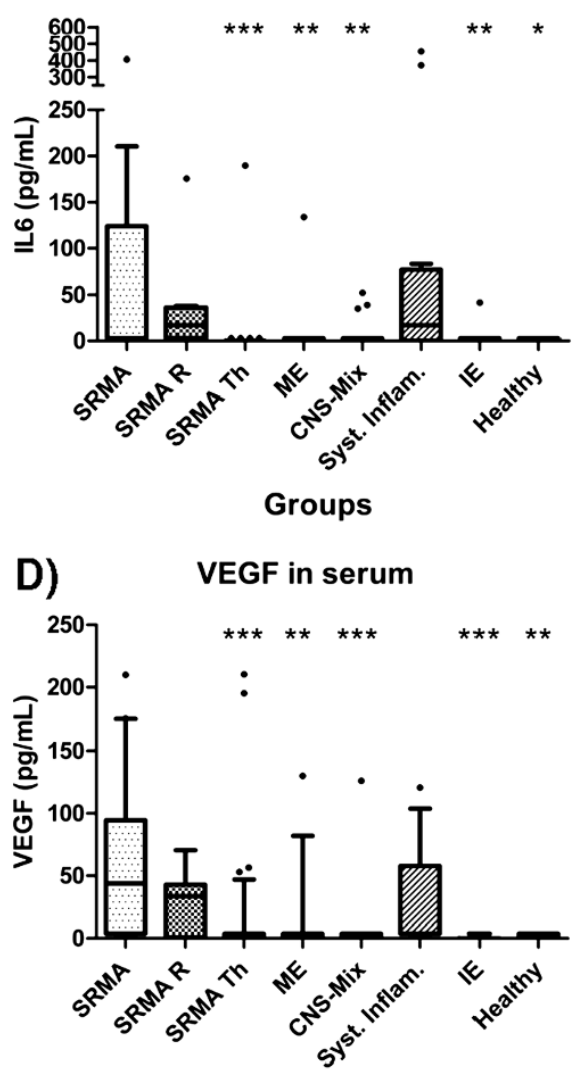

Groups

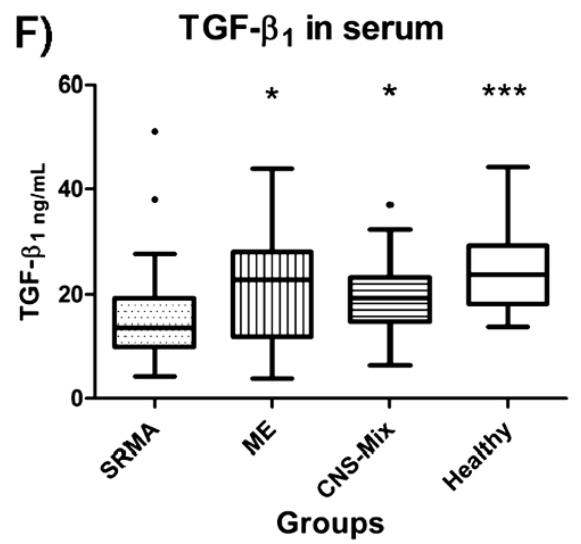

Figure 1 Quantification of signalling proteins. Quantification of signalling proteins: IL-6 in CSF (A) and serum (B), VEGF in CSF (C) and serum (D), TGF- $\beta_{1}$ in CSF (E) and serum (F). Boxes contain values from 1st to 3rd quartile, lines inside boxes indicate median values, endpoints of vertical lines display 5 th- $95^{\text {th }}$ percentile and $\cdot$ represent the outliers. Asterisks indicate statistically significant differences from the disease category 'SRMA untreated' (* $P<0.05$; ** $P<0.01$; ** $P<0.005$ ). IL-6: interleukin-6; VEGF: vascular endothelial grow factor; TGF- $\beta_{1}$ : Transforming growth factor beta 1. CSF cerebrospinal fluid; CNS: central nervous system; SRMA: steroid-responsive meningitis-arteritis; ME: other inflammatory CNS diseases; CNSMix: miscellaneous non-inflammatory CNS diseases; Syst Inflam: systemic inflammatory diseases; IE: idiopathic epilepsy.

\section{Correlation analysis}

The data of the parameters correlating with the signalling proteins within the untreated SRMA group are shown in Table 4. A summary of the statistically relevant correlations found in the 'SRMA' group is shown in
Table 5. A weak positive correlation between signalling protein and IgA concentration was found between CSF TGF- $\beta_{1}$ and CSF IgA ( $\left.\mathrm{r}_{\text {Spear }}=0.3549 ; P=0.0337\right)$.

CSF concentrations of IL-6 and VEGF had a strong positive correlation with the degree of pleocytosis 
Table 3 Concentration of signalling proteins in different disease categories

\begin{tabular}{|c|c|c|c|c|c|c|c|c|c|}
\hline & & SRMA & SRMA R & SRMA Th & Syst Inflam & $\mathrm{ME}$ & CNS-Mix & IE & Healthy \\
\hline \multirow[t]{4}{*}{ IL-6 } & CSF & 1582 & 637.7 & 0 & 0 & 3 & 0 & 0 & 3 \\
\hline & $(\mathrm{pg} / \mathrm{mL})$ & $(163.1-3473)$ & $(17.19-1507)$ & $(0-1.5)$ & $(0-31.25)$ & $(0-175.6)$ & $(0-3)$ & $(0-3)$ & $(0.75-3)$ \\
\hline & Serum & 3 & 17.13 & 0 & 17.13 & 0 & 0 & 1.5 & 3 \\
\hline & (pg/mL) & $(3-124)$ & $(3-36.24)$ & $(0-0)$ & $(0-77.1)$ & $(0-3)$ & $(0-3)$ & $(0-3)$ & $(0-3)$ \\
\hline \multirow[t]{4}{*}{ VEGF } & CSF & 36.31 & 20.80 & 0 & 0 & 0 & 0 & 0 & 0 \\
\hline & $(\mathrm{pg} / \mathrm{mL})$ & $(1-175.2)$ & $(0-69.96)$ & $(0-0)$ & $(0-0)$ & $(0-65.71)$ & $(0-0)$ & $(0-0)$ & $(0-0)$ \\
\hline & Serum & 43.92 & 33.71 & 3.9 & 3.9 & 0 & 0 & 0 & 3.9 \\
\hline & $(\mathrm{pg} / \mathrm{mL})$ & (3.9-94.5) & $(0.98-42.9)$ & $(0-3.9)$ & (3.9-57.8) & $(0-3.9)$ & $(0-3.9)$ & $(0-0)$ & $(1.95-3.9)$ \\
\hline \multirow[t]{4}{*}{ TGF- $\beta_{1}$} & CSF & 90 & n.a. & n.a. & n.a. & 58 & 0 & n.a. & 0 \\
\hline & $(\mathrm{pg} / \mathrm{mL})$ & $(0-429)$ & & & & $(0-214)$ & $(0-95)$ & & $(0-0)$ \\
\hline & Serum & 13.57 & n.a. & n.a. & n.a. & 22.84 & 19.31 & n.a. & 23.84 \\
\hline & $(\mathrm{ng} / \mathrm{mL})$ & $(9.93-19.27)$ & & & & $(11.86-27.96)$ & $(14.77-23.25)$ & & $(18.19-29.1$ \\
\hline
\end{tabular}

IL-6: interleukin-6; VEGF: vascular endothelial grow factor; TGF- $\beta_{1}$ : Transforming growth factor beta; CSF: cerebrospinal fluid; CNS: central nervous system; SRMA: steroid-responsive meningitis-arteritis; Syst Inflam: systemic inflammatory diseases; ME: other inflammatory CNS diseases; CNS-Mix: miscellaneous non-inflammatory CNS diseases; IE: idiopathic epilepsy; n.a.: not available. Data are given as median and range (25th-75th percentile).

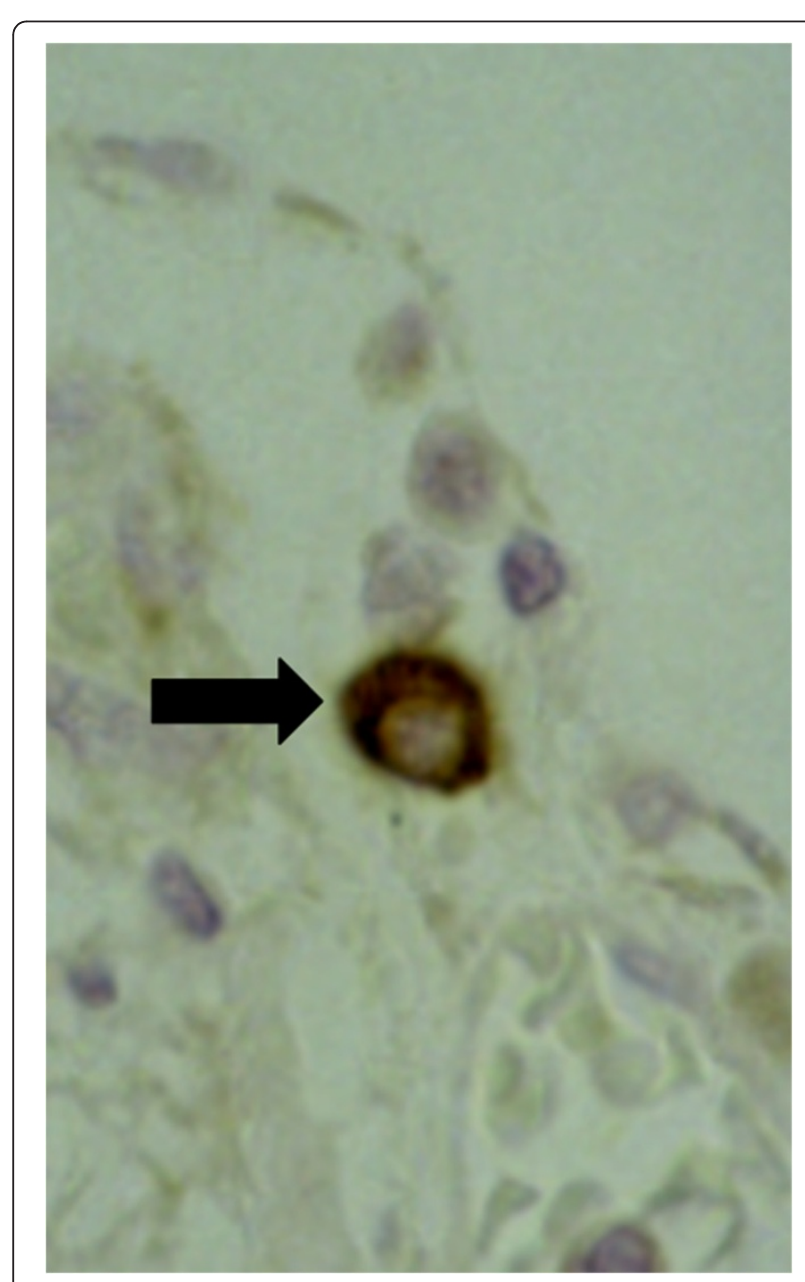

Figure 2 Spinal cord and meninges of a dog with SRMA. Arrow indicates TGF- $\beta_{1}$ positive lymphocyte; immunohistochemistry, antiTGF- $\beta_{1}-A B C, \times 400$. SRMA: steroid-responsive meningitis-arteritis. TGF$\beta_{1}$ : Transforming growth factor beta 1 . $\left(\mathrm{r}_{\text {Spear }}=0.8323 ; P<0.0001\right.$ and $\mathrm{r}_{\text {Spear }}=0.5711 ; P=0.0166$, respectively). A strong positive correlation was also found between concentration of IL- 6 and VEGF, both in CSF $\left(\mathrm{r}_{\text {Spear }}=0.8246 ; P<0,0001\right)$ and serum $\left(\mathrm{r}_{\text {Spear }}=0.5045\right.$; $P=0.0086)$. A similar correlation was not found in serum of 'Syst Inflam.' group $\left(\mathrm{r}_{\text {Spear }}=0.1340 ; P=0.339\right)$.

\section{Discussion}

The aim of the present study was to investigate the role of IL- 6 , VEGF and TGF- $\beta_{1}$ in the pathogenesis of SRMA.

VEGF concentrations were measured, since this parameter has been widely studied in human patients affected with Kawasaki Disease (KD), an acute febrile systemic vasculitis of children. SRMA has been proposed as an animal model for KD [30,31]. In KD patients, concentrations of VEGF were found significantly elevated $[16,17,32]$. The histopathology of meningeal arteries of dogs euthanised during the acute stage of SRMA typically revealed endothelial and subendothelial oedema, hyaline degeneration and a mild to moderate periarteritis [33]. Therefore, we hypothesized that elevated VEGF might cause these early vascular changes. Indeed, our results showed that VEGF was increased both systemically

Table 4 Parameters investigated for the group 'SRMA'

\begin{tabular}{|c|c|c|c|}
\hline \multicolumn{2}{|c|}{ Concentration of $\lg A$} & \multicolumn{2}{|c|}{ Number of leukocytes } \\
\hline CSF & 2 & CSF & 1532 \\
\hline$(\mu \mathrm{g} / \mathrm{mL})$ & $(0.86-3.1)$ & cells $/ 3 \mu \mathrm{L})$ & $(548-3720)$ \\
\hline Serum & 167.4 & PB & 25635 \\
\hline$(\mu \mathrm{g} / \mathrm{mL})$ & $(98.90-404.5)$ & (cells/ $\mu \mathrm{L})$ & $(17250-31533)$ \\
\hline
\end{tabular}

CSF: cerebrospinal fluid; SRMA: steroid-responsive meningitis-arteritis; PB: peripheral blood. Data are given as median and range (25th-75th percentile). 
Table 5 Significant correlations for the group 'SRMA'

\begin{tabular}{lll}
\hline Evaluated parameters & & Spearman's rank correlation coefficient \\
\hline Concentration of IL-6 in CSF & Concentration of VEGF in CSF & $0.8246^{* * *}$ \\
\hline Concentration of IL-6 in serum & Concentration of VEGF in serum & $0.5045^{* *}$ \\
\hline Concentration of IL-6 in CSF & Number of leukocytes in CSF & $0.8323^{* *}$ \\
\hline Concentration of VEGF in CSF & Number of leukocytes in CSF & $0.5711^{*}$ \\
\hline Concentration of TGF- $\beta_{1}$ in CSF & Concentration of IgA in CSF & $0.3549^{*}$ \\
\hline
\end{tabular}

SRMA: steroid-responsive meningitis-arteritis; IL-6: interleukin-6; VEGF: vascular endothelial grow factor; TGF- $\beta_{1}$ : Transforming growth factor beta; IgA: immunoglobulin A; CSF: cerebrospinal fluid. Data are given as median and range (25th-75th percentile).

${ }^{*} P<0.05$; ** $P<0.01$; *** $P<0.005$.

and intrathecally in SRMA patients during the clinical phases of the disease ('SRMA' and 'SRMA R'). At these time points the mentioned vascular changes can be observed [33].

In other different inflammatory processes within the CNS ("ME" group), VEGF was found to be increased only in single cases, but overall the CSF VEGF concentrations in this group was significantly lower than in the SRMA group. We might conclude that VEGF does not play an important role in other meningoencephalomyelitides. However, due to the heterogeneity of the diseases included in the ME group (e.g. granulomatous meningoencephalomyelitis, necrotising encephalitides and meningoencephalomyelitis of unknown origin) we can not exclude from this study a role for VEGF in some of these diseases.

The values of VEGF in cases with systemic inflammation were lower than in dogs with SRMA (median $3.9 \mathrm{pg} / \mathrm{mL}$ and $43.92 \mathrm{pg} / \mathrm{mL}$, respectively). However, the difference was not statistically significant. This is in accordance with a recent study in which VEGF values were elevated in $64 \%$ of dogs with systemic inflammatory response syndrome. However, a correlation with clinical signs or increased permeability could not be proved [20].

VEGF is involved in the proposed pathogenesis of vasculitis in KD. After the permeability of the vessels is increased under to the influence of VEGF, platelets might adhere to the vascular wall and inflammatory cells cross the loose endothelium, accumulating in the intima and becoming a source of proinflammatory cytokines. As final consequence there is a thickening of the intima as found in both diseases, KD and SRMA. If coronary artery lesions occur, this might even lead to lifethreatening complications [31]. In KD patients VEGF was correlated with the development of coronary artery lesions [32].

Interestingly in our study VEGF was not only found increased in the acute stage of SRMA, but also during relapses of SRMA (median in CSF $20.80 \mathrm{pg} / \mathrm{mL}$; median in serum $33.71 \mathrm{pg} / \mathrm{mL}$ ). Therefore, VEGF in SRMA may enhance vascular wall destruction in the acute phase of the disease before immune complexes appear [33]. However, further in vitro studies evaluating directly the effect of VEGF on canine vasculature (e.g. using endothelial cells culture or cultured vessels) are needed to confirm the role of this protein in the pathogenesis of canine arteritis.

Since VEGF concentrations were increased during relapses, consequently, VEGF may be also involved in the development of the arterial lesions found during the chronic phase, such as increased wall thickness, stenosis and fibrosis [33]. On the other hand, VEGF might indicate simply vascular damage. A limitation of this study is the lack of comparison to other pure vasculitides. Experimental in vivo studies are probably necessary to elucidate the long-term effect of VEGF on canine vessels. Experimental studies on SRMA dogs are feasible, due to the natural occurrence and the favourable prognosis of the disease.

The recruitment and activation of different lymphocytes subsets after alteration of the CNS tissue by an environmental factor are caused by multiple mechanisms [34]. These include chemotactic agents [35], probably additional mechanisms such as changes of the bloodbrain barrier [36,37], and altered expression of selectins and integrins $[38,39]$. To add more information to these previous studies and to investigate the hypothesis that IL-6 and TGF- $\beta_{1}$ are correlated to and eventually involved in the pathogenesis of fever, pleocytosis and increased IgA production in SRMA, these proteins were determined in CSF and serum samples. Previous studies on cytokine expression in SRMA patients, showed an up-regulation of IL-4 and IL-8, while IL- 2 and IFN- $\gamma$ were found in low concentrations [12,35]. Hogenesch et al. [40] investigated IL-6 in serum of dogs with juvenile polyarteritis syndrome and detected increased IL-6 serum values. In preliminary studies, measurement of IL-6 in CSF was considered to be a valuable biomarker for the diagnosis of SRMA [41]. Qualitative studies containing information about the bioactivity of IL-6 in CSF were missing.

In the current study IL-6 values were increased intrathecally and systemically in SRMA patients, the highest concentrations were found in CSF samples (median $1582 \mathrm{pg} / \mathrm{mL}$ in 'SRMA' and median $637.7 \mathrm{pg} / \mathrm{mL}$ in the 'SRMA R' groups). In case of other inflammatory 
diseases of the CNS ('ME' group) the concentrations of CSF IL-6 were significantly lower (median $3 \mathrm{pg} / \mathrm{mL}$ ), leading to the conclusion that IL-6 is an important biomarker for disease activity in SRMA. The exact role of IL-6 in the pathogenesis of the disease could be investigated in experimental studies. Further, IL-6 in SRMA strongly correlated with the degree of pleocytosis. This fact might also suggests, that IL- 6 values might be the result of the severe pleocytosis because of its production by macrophages [23]. Lowrie et al. [41] also detected elevated IL-6 CSF values in samples of dogs with a putative relapse and a normal CSF cell count, making the latter hypothesis less likely, nevertheless further studies should be addressed to clarify causes and consequences.

IL-6 has long-range effects, indeed it is one of the most important endogenous pyrogens, induces hepatocytes to synthesize acute-phase proteins, stimulates neutrophil mobilization from bone marrow and stimulates terminal differentiation of $\mathrm{B}$ cells to secret immunoglobulins $[23,42,43]$. Therefore it is very likely that an overproduction of IL-6 is a major mediator of the most peculiar findings, such as fever, increased acute-phase proteins, CSF neutrophilic pleocytosis and peripheral leukocytosis as well as increased IgA production during the acute phase of SRMA. The extreme high values of IL-6 in CSF also during relapses suggest that IL-6 exerts its major functions intrathecally and throughout the waxing and waning course of the disease. As previously mentioned, the cell population in CSF of dogs during the acute phase of SRMA is predominantly composed of neutrophils, during the chronic form macrophages tend to prevail. Upregulation of CD11a on neutrophils [39], increased IL-8 levels in CSF [35] and the destruction of the blood-brain barrier [44] have all been shown to be involved in neutrophil migration into CSF. Factors involved in the accumulation of monocytes in CSF of SRMA patients during the protracted form have not been investigated. Interestingly, IL-6 has been recently proposed to be a regulator of the transition from a neutrophil-dominated to a macrophage-dominated process [45]. We therefore propose a leading role for IL-6 in both the acute and protracted forms of the disease.

As expected, serum IL-6 concentrations were similar to the group of systemic inflammatory diseases supporting other studies, where IL- 6 has been used not only as a general marker of inflammation [26], but in particular as a prognostic factor in canine systemic inflammatory response syndrome and sepsis [27]. Also in KD IL-6 is increased in serum, but contrary to VEGF, the increase was not correlated with the development of coronary artery aneurysms and dilatation [46,47].

In SRMA dogs both VEGF and IL-6 were much higher in CSF compared to serum values. This might reflect a more severe inflammatory process affecting meninges and meningeal vessels compared to peripheral vessels, or a main intrathecal production of these signalling proteins, followed by a secondary leakage into the systemic circulation. Further studies including protein associated gene expression and immunohistochemistry of meningeal and peripheral vessels might be necessary to elucidate the site of production.

TGF- $\beta_{1}$ in SRMA patients was decreased in serum (median $13.57 \mathrm{ng} / \mathrm{mL}$ ) and elevated in CSF (median $90 \mathrm{pg} / \mathrm{mL}$ ). The increased concentration in CSF was not specific for SRMA, indeed similar values have been found in other meningoencephalomyelitides (median $58 \mathrm{pg} / \mathrm{mL}$ ), while the reduced concentration in serum statistically differed from the other groups.

The serum concentrations of TGF- $\beta_{1}$ were found to be decreased also in patients with KD [48], but to the authors knowledge data concerning concentrations of TGF- $\beta_{1}$ in CSF of patients with KD are lacking. The hypothesis that TGF- $\beta_{1}$ might be the most important pathogenetic factor for the excessive IgA production in SRMA could be partially rejected in the current study. Our results support the suggestion that TGF- $\beta_{1}$ has a minor role in systemic production of IgA, whereas it is highly likely that it might still play a certain role in the intrathecal production of IgA. Indeed, TGF- $\beta_{1}$ was positively correlated with IgA concentrations in CSF $\left(\mathrm{r}_{\text {Spear }}=\right.$ $0.3549 ; P=0.0337)$. However, CSF IgA concentrations remain high during teatment $[5,8,10]$ and concentration of TGF- $\beta_{1}$ decline. Therefore, this rather unspecific elevation of TGF- $\beta_{1}$ values in CSF samples supports a more immunoregulatory function of this cytokine in inflammatory CNS diseases [49,50]. Further experimental in vivo and in vitro studies are needed to confirm this hypothesis.

Our findings indicate that the CSF cytokine profile of SRMA dogs during the acute phase is characterized by increased values of IL- 6 and TGF- $\beta_{1}$. Recent progress in immunology led to the discovery of Th17 cells, a new subset of $\mathrm{T}$ helper cells [51,52]. According to one study, the combined influence of both IL- 6 and TGF- $\beta_{1}$ is necessary for the Th17 lineage to develop, while TGF- $\beta_{1}$ alone shifts the development of naïve T-cells towards $\mathrm{T}$ regulatory cells, a T-cell subset that restrains inflammation and maintains tolerance [53].

The detected combined high intrathecal production of TGF- $\beta_{1}$ and IL- 6 in SRMA could possibly lead to an increase of Th17 lymphocyte subset and subsequently enhance the development of an autoimmune response. IL-17, the main product of this lymphocyte subset, plays an active role in inflammatory response and in autoimmune diseases [54] and experimental studies displayed a neutrophil-mobilizing mechanism of IL-17A [55]. The massive invasion of neutrophils into the subarachnoidal space in SRMA dogs might be the results of a Th17 immune response. Further studies to prove direct evidence 
of Th17 cells and its products in SRMA patients have to be conducted.

To date, SRMA has been believed to be a Th2mediated immune disorder [12], our results suggest indirectly that in SRMA a Th17 skewed immune response might play a major role, particularly in the development of the meningitis.

\section{Conclusions}

Analysis of the pattern of signalling proteins production in SRMA showed many similarities with results in KD supporting the usefulness of this animal model. In our study increased concentrations of VEGF and IL-6 in serum and CSF of dogs affected with SRMA were found. TGF- $\beta_{1}$ was increased in CSF and decreased in serum. This study produces evidence that these three signalling proteins are biomarkers of disease activity in SRMA. VEGF might be involved in the pathogenesis of vasculitis, especially in a pronounced permeability and vessel wall damage. TGF- $\beta_{1}$ is considered to be involved in the excessive IgA production. However, the presented data indicate that additional proteins may influence IgA production. Pleocytosis in SRMA dogs is supported by extremely high intrathecal IL-6 production; a similar pathomechanism might be responsible for the continuous ongoing of the disease and the invasion of neutrophils. The hypothesis that SRMA might be a Th17-mediated disorder should be further investigated.

\footnotetext{
Abbreviations

CBC: Complete blood cell count; CNS: Central nervous system; CNSMix: Miscellaneous non-inflammatory diseases of the CNS; CSF: Cerebrospinal fluid; ELISA: Enzyme-linked immunosorbent assays; IE: Idiopathic epilepsy; IgA: Immunoglobulin A; LL: Interleukin; KD: Kawasaki Disease; ME: Meningoencephalomyelitides; rcIL-6: Recombinant canine IL-6; $r_{\text {Spear: }}$ Spearman's rank correlation coefficient; SRMA: Steroid responsive meningitis-arteritis; SRMA R: SRMA relapse; SRMA Th: SRMA therapy; Syst. Infl.: Systemic inflammatory diseases; TGF- $\beta_{1}$ : Transforming growth factor beta 1; Th: T helper cells; TNF: Tumor necrosis factor; VEGF: Vascular endothelial growth factor.
}

\section{Competing interests}

The authors declare that they have no competing interests.

\section{Authors' contributions}

AT designed and supervised the study. AM performed the experiments and analysed the data concerning the part of VEGF and IL-6. OT performed the experiments and analysed the data concerning the part of TGF- $\beta_{1}$. RC gave substantial contributions to acquisition, analysis and interpretation of the data in all the experiments. MHT provided the laboratory, materials, supervision and substantial contribution to acquisition of the data for the immunohistochemical part of the experiment on TGF- $\beta_{1}$. AM drafted the manuscript and all authors contributed to the critical revision of the manuscript for important intellectual content and have read and approved the final version.

\section{Acknowledgements}

This study was supported by grants from the association for promotion of cynologic research (Gesellschaft zur Förderung Kynologischer Forschung, GKF - Germany) and the Joachim and Irene Hahn Foundation (Joachim und Irene Hahn-Stiftung - Hannover - Germany).
The authors are grateful to the whole staff of the Neurology Service of the Department of Small Animal Medicine and Surgery, University of Veterinary Medicine, Hannover, Germany helping examining the animals and collecting the samples.

\section{Author details}

${ }^{1}$ Department of Small Animal Medicine and Surgery, University of Veterinary Medicine, Hannover, Germany. ${ }^{2}$ Center for Systems Neuroscience, Hannover, Germany. ${ }^{3}$ Veterinary Practice Peter Gravert and Dr. Volker Otten, Gettorf, Germany. ${ }^{4}$ Department of Pathology, University of Veterinary Medicine, Hannover, Germany.

Received: 16 January 2012 Accepted: 28 January 2013 Published: 4 February 2013

\section{References}

1. Tipold A: Diagnosis of inflammatory and infectious diseases of the central nervous system in dogs: a retrospective study. J Vet Intern Med 1995, 9(5):304-314.

2. Muñana KR: Encephalitis and meningitis. Vet Clin North Am Small Anim Pract 1996, 26(4):857-874.

3. Meric SM: Canine meningitis. A changing emphasis. J Vet Intern Med 1988, 2(1):26-35.

4. Battersby IA, Murphy KF, Tasker S, Papasouliotis K: Retrospective study of fever in dogs: laboratory testing, diagnoses and influence of prior treatment. J Small Anim Pract 2006, 47(7):370-376.

5. Cizinauskas S, Jaggy A, Tipold A: Long-term treatment of dogs with steroid-responsive meningitis-arteritis: clinical, laboratory and therapeutic results. J Small Anim Pract 2000, 41(7):295-201.

6. Bathen-Noethen A, Carlson R, Menzel D, Mischke R, Tipold A: Concentrations of acute-phase proteins in dogs with steroid responsive meningitis-arteritis. J Vet Intern Med 2008, 22(5):1149-1156.

7. Lowrie M, Penderis J, Eckersall PD, McLaughlin M, Mellor D, Anderson TJ: The role of acute phase proteins in diagnosis and management of steroid-responsive meningitis arteritis in dogs. Vet J 2009, 182(1):125-130.

8. Lowrie M, Penderis J, McLaughlin M, Eckersall PD, Anderson TJ: Steroid responsive meningitis-arteritis: a prospective study of potential disease markers, prednisolone treatment, and long-term outcome in 20 dogs (2006-2008). J Vet Intern Med 2009, 23(4):862-870.

9. Tipold A, Pfister H, Zurbriggen A, Vandevelde M: Intrathecal synthesis of major immunoglobulin classes in inflammatory diseases of the canine CNS. Vet Immunol Immunopathol 1994, 42(2):149-159.

10. Maiolini A, Carlson R, Schwartz M, Gandini G, Tipold A: Determination of immunoglobulin a concentrations in the serum and cerebrospinal fluid of dogs: an estimation of its diagnostic value in canine steroidresponsive meningitis-arteritis. Vet J 2011. doi:10.1016/j.tvjl.2010.1012.1018.

11. Schwartz M, Moore PF, Tipold A: Disproportionally strong increase of $B$ cells in inflammatory cerebrospinal fluid of dogs with Steroid-responsive Meningitis-Arteritis. Vet Immunol Immunopathol 2008, 125(3-4):274-283.

12. Schwartz M, Puff C, Stein VM, Baumgartner W, Tipold A: Pathogenetic factors for excessive IgA production: Th2-dominated immune response in canine steroid-responsive meningitis-arteritis. Vet J 2011 187(2):260-266.

13. Dvorak HF, Brown LF, Detmar M, Dvorak AM: Vascular permeability factor/ vascular endothelial growth factor, microvascular hyperpermeability, and angiogenesis. Am J Pathol 1995, 146(5):1029-1039.

14. Nagy JA, Benjamin L, Zeng H, Dvorak AM, Dvorak HF: Vascular permeability, vascular hyperpermeability and angiogenesis. Angiogenesis 2008, 11(2):109-119.

15. Monach PA, Tomasson G, Specks U, Stone JH, Cuthbertson D, Krischer J, Ding L, Fervenza FC, Fessler BJ, Hoffman GS, et al: Circulating markers of vascular injury and angiogenesis in ANCA-associated vasculitis. Arthritis Rheum 2011, 63(12):3988-3997.

16. Terai M, Yasukawa K, Narumoto S, Tateno S, Oana S, Kohno Y: Vascular endothelial growth factor in acute Kawasaki disease. Am J Cardiol 1999, 83(3):337-339.

17. Yasukawa K, Terai M, Shulman ST, Toyozaki T, Yajima S, Kohno Y, Rowley AH: Systemic production of vascular endothelial growth factor and fms-like tyrosine kinase-1 receptor in acute Kawasaki disease. Circulation 2002, 105(6):766-769. 
18. Lin JD, Chao TC: Vascular endothelial growth factor in thyroid cancers. Cancer Biother Radiopharm 2005, 20(6):648-661.

19. Saharinen P, Eklund L, Pulkki K, Bono P, Alitalo K: VEGF and angiopoietin signaling in tumor angiogenesis and metastasis. Trends Mol Med 2011, 17(7):347-362

20. Silverstein DC, Montealegre C, Shofer FS, Otto CM: The association between vascular endothelial growth factor levels and clinically evident peripheral edema in dogs with systemic inflammatory response syndrome. J Vet Emerg Crit Care (San Antonio) 2009, 19(5):459-466.

21. Al-Dissi AN, Haines DM, Singh B, Kidney BA: Immunohistochemical expression of vascular endothelial growth factor and vascular endothelial growth factor receptor-2 in canine simple mammary gland adenocarcinomas. Can Vet J 2010, 51(10):1109-1114.

22. Clifford CA, Hughes D, Beal MW, Mackin AJ, Henry CJ, Shofer FS, Sorenmo $\mathrm{KU}$ : Plasma vascular endothelial growth factor concentrations in healthy dogs and dogs with hemangiosarcoma. J Vet Intern Med 2001, 15(2):131-135.

23. Murphy K, Travers P, Walport M: Innate Immunity. In: Janeway's Immunobiology. 7th edition. New York: Garland Science, Taylor \& Francis Group; 2008:39-108.

24. Murphy K, Travers P, Walport M: The mucosal Immune System. In: Janeway's Immunobiology. 7th edition. New York: Garland Science, Taylor \& Francis Group; 2008:459-495.

25. Carter SD, Barnes A, Gilmore WH: Canine rheumatoid arthritis and inflammatory cytokines. Vet Immunol Immunopathol 1999, 69(2-4):201-214

26. LeMay DR, LeMay LG, Kluger MJ, D'Alecy LG: Plasma profiles of IL-6 and TNF with fever-inducing doses of lipopolysaccharide in dogs. Am J Physiol 1990, 259(1 Pt 2):R126-132.

27. Rau S, Kohn B, Richter C, Fenske N, Kuchenhoff H, Hartmann K, Hartle S, Kaspers B, Hirschberger J: Plasma interleukin-6 response is predictive for severity and mortality in canine systemic inflammatory response syndrome and sepsis. Vet Clin Pathol 2007, 36(3):253-260.

28. Aarden LA, De Groot ER, Schaap OL, Lansdorp PM: Production of hybridoma growth factor by human monocytes. Eur I Immunol 1987, 17(10):1411-1416.

29. Manning AM, Auchampach JA, Drong RF, Slightom JL: Cloning of a canine cDNA homologous to the human transforming growth factor-beta 1encoding gene. Gene 1995, 155(2):307-308.

30. Burns JC, Felsburg PJ, Wilson H, Rosen FS, Glickman LT: Canine pain syndrome is a model for the study of Kawasaki disease. Perspect Biol Med 1991, 35(1):68-73.

31. Burns JC, Glode MP: Kawasaki syndrome. Lancet 2004, 364(9433):533-544.

32. Kariyazono H, Ohno T, Khajoee V, Ihara K, Kusuhara K, Kinukawa N, Mizuno $Y$, Hara T: Association of vascular endothelial growth factor (VEGF) and VEGF receptor gene polymorphisms with coronary artery lesions of Kawasaki disease. Pediatr Res 2004, 56(6):953-959.

33. Tipold A, Vandevelde M, Zurbriggen A: Neuroimmunological studies in steroid-responsive meningitis-arteritis in dogs. Res Vet Sci 1995, 58(2):103-108

34. Tipold A, Moore P, Zurbriggen A, Vandevelde M: Lymphocyte subset distribution in steroid responsive meningitis-arteriitis in comparison to different canine encephalitides. Zentralbl Veterinarmed A 1999, 46(2):75-85.

35. Burgener I, Van Ham L, Jaggy A, Vandevelde M, Tipold A: Chemotactic activity and IL-8 levels in the cerebrospinal fluid in canine steroid responsive meningitis-arteriitis. J Neuroimmunol 1998, 89(1-2):182-190.

36. Lacy M, Jones J, Whittemore SR, Haviland DL, Wetsel RA, Barnum SR: Expression of the receptors for the C5a anaphylatoxin, interleukin-8 and FMLP by human astrocytes and microglia. J Neuroimmunol 1995, 61(1):71-78.

37. Sprenger H, Rosler A, Tonn P, Braune HJ, Huffmann G, Gemsa D: Chemokines in the cerebrospinal fluid of patients with meningitis. Clin Immunol Immunopathol 1996, 80(2):155-161.

38. Granger DN, Kubes P: The microcirculation and inflammation: modulation of leukocyte-endothelial cell adhesion. J Leukoc Biol 1994, 55(5):662-675.

39. Schwartz M, Carlson R, Tipold A: Selective CD11a upregulation on neutrophils in the acute phase of steroid-responsive meningitis-arteritis in dogs. Vet Immunol Immunopathol 2008, 126(3-4):248-255.

40. Hogenesch H, Snyder PW, Scott-Moncrieff JC, Glickman LT, Felsburg PJ: Interleukin-6 activity in dogs with juvenile polyarteritis syndrome: effect of corticosteroids. Clin Immunol Immunopathol 1995, 77(1):107-110.
41. Lowrie M, Penderis J, Lappin DF, Anderson TJ: Is traditional CSF analysis the gold standard for confirming CNS inflammation? Evidence from CSF IL-6 concentrations. In: Proceedings of the 21th Annual Symposium ESVN/ ECVN: 25-27 September 2008; Rhodes; 2008:49-50.

42. Naka T, Nishimoto N, Kishimoto T: The paradigm of IL-6: from basic science to medicine. Arthritis Res 2002, 4(Suppl 3):S233-242.

43. Tizard IR: Immunity at Body Surfaces. In: Veterinary immunology: an introduction. 7th edition. Philadelphia, Pa: Saunders; 2004:234-246.

44. Schwartz M, Puff C, Stein VM, Baumgartner W, Tipold A: Marked MMP-2 transcriptional up-regulation in mononuclear leukocytes invading the subarachnoidal space in aseptic suppurative Steroid-Responsive Meningitis-Arteritis in dogs. Vet Immunol Immunopathol 2010, 133(2-4):198-206.

45. Kaplanski G, Marin V, Montero-Julian F, Mantovani A, Farnarier C: IL-6: a regulator of the transition from neutrophil to monocyte recruitment during inflammation. Trends Immunol 2003, 24(1):25-29.

46. Kim DS: Serum interleukin-6 in Kawasaki disease. Yonsei Med J 1992 33(2):183-188.

47. Lin CY, Lin CC, Hwang B, Chiang B: Serial changes of serum interleukin-6, interleukin-8, and tumor necrosis factor alpha among patients with Kawasaki disease. J Pediatr 1992, 121(6):924-926.

48. Matsubara T, Umezawa Y, Tsuru S, Motohashi T, Yabuta K, Furukawa S: Decrease in the concentrations of transforming growth factor-beta 1 in the sera of patients with Kawasaki disease. Scand J Rheumatol 1997, 26(4):314-317

49. Bettelli E, Carrier Y, Gao W, Korn T, Strom TB, Oukka M, Weiner HL, Kuchroo VK: Reciprocal developmental pathways for the generation of pathogenic effector TH17 and regulatory T cells. Nature 2006, 441(7090):235-238.

50. Murphy K, Travers P, Walport M: T Cell-Mediated immunity. In: Janeway's Immunobiology. 7th edition. New York: Garland Science, Taylor \& Francis Group; 2008:323-377.

51. Harrington LE, Hatton RD, Mangan PR, Turner H, Murphy TL, Murphy KM, Weaver CT: Interleukin 17-producing CD4+ effector T cells develop via a lineage distinct from the Thelper type 1 and 2 lineages. Nat Immunol 2005, 6(11):1123-1132.

52. Park H, Li Z, Yang XO, Chang SH, Nurieva R, Wang YH, Wang Y, Hood L, Zhu Z, Tian $Q$, et al: A distinct lineage of CD4 T cells regulates tissue inflammation by producing interleukin 17. Nat Immunol 2005, 6(11):1133-1141.

53. Bettelli $E$, Korn T, Kuchroo VK: Th17: the third member of the effector $T$ cell trilogy. Curr Opin Immunol 2007, 19(6):652-657.

54. Kolls JK, Linden A: Interleukin-17 family members and inflammation. Immunity 2004, 21(4):467-476.

55. Lubberts E, Joosten LA, Oppers B, van den Bersselaar L, Coenen-de Roo CJ, Kolls JK, Schwarzenberger P, van de Loo FA, van den Berg WB: IL-1independent role of IL-17 in synovial inflammation and joint destruction during collagen-induced arthritis. J Immunol 2001, 167(2):1004-1013.

doi:10.1186/1746-6148-9-23

Cite this article as: Maiolini et al:: Interleukin-6, vascular endothelial growth factor and transforming growth factor beta 1 in canine steroid responsive meningitis-arteritis. BMC Veterinary Research 2013 9:23.

\section{Submit your next manuscript to BioMed Central and take full advantage of:}

- Convenient online submission

- Thorough peer review

- No space constraints or color figure charges

- Immediate publication on acceptance

- Inclusion in PubMed, CAS, Scopus and Google Scholar

- Research which is freely available for redistribution 